OPEN ACCESS

Edited by:

Dan H. Shugar,

University of Calgary, Canada

Reviewed by:

Nicholas Roberts,

Simon Fraser University, Canada

José Pedro Matos,

Stucky SA, Switzerland

*Correspondence:

Alex Strouth

astrouth@bgcengineering.ca

Specialty section:

This article was submitted to

Geohazards and Georisks,

a section of the journal

Frontiers in Earth Science

Received: 15 September 2020

Accepted: 11 January 2021

Published: 18 February 2021

Citation:

Strouth A and McDougall S (2021) Historical Landslide Fatalities in British

Columbia, Canada: Trends and

Implications for Risk Management.

Front. Earth Sci. 9:606854.

doi: 10.3389/feart.2021.606854

\section{Historical Landslide Fatalities in British Columbia, Canada: Trends and Implications for Risk Management}

\author{
Alex Strouth ${ }^{1,2 *}$ and Scott McDougall ${ }^{1}$ \\ ${ }^{1}$ Department of Earth, Ocean and Atmospheric Sciences, The University of British Columbia, Vancouver, BC, Canada, ${ }^{2}$ BGC \\ Engineering Inc., Golden, CO, United States
}

According to a Canadian government database, landslides are the most common type of disaster that occurs in the province of British Columbia. Recently there has been a trend in British Columbia toward using quantitative risk assessments to estimate life-loss risk at landslide hazard sites, and to compare these estimates with risk tolerance thresholds to determine the necessity for, and extent of, risk management measures. These risk estimates are most often calibrated by so-called 'expert judgment' because historical landslide fatality data are not readily available. This article addresses this gap by summarizing available historical data to better inform expert judgment. It shows that fatalities caused by landslides in British Columbia are rare (approximately one fatality per year in the last decade) and have decreased with time despite rapid population growth. Approximately half of these fatalities in the last decade are related to debris flows and debris floods that impact houses, whereas the other half are related to rockfalls, debris flows, and debris floods that impact highways. A comparison with other hazard types in the Canadian government's disaster database suggests that, while not particularly deadly, landslides are still important because of the economic damage and service disruptions they cause. Although the data are specific to British Columbia, the methods for identifying and presenting landslide risk trends could be modified and adopted in other world regions where landslide fatality data are collected and quantitative risk management methods are utilized.

Keywords: landslide risk, quantitative risk assessment, FN curve, loss of life, landslide fatalities, disasters

\section{INTRODUCTION}

There is increasing advocacy for forward-looking and action-oriented approaches to risk management and disaster risk reduction. This idea has been formalized, for example, in the Sendai Framework for Disaster Risk Reduction (United Nations Office of Disaster Risk Reduction, 2015) and is central to British Columbia, Canada's current efforts to modernize its emergency management legislation (British Columbia, 2019). Accordingly, a quantitative risk management framework for landslide hazards is gaining wider adoption in the province of British Columbia, particularly with a focus on life-loss risk (Porter et al., 2017; Strouth and McDougall, 2020). The centerpiece of this framework is landslide risk assessment, which estimates, in part, how many people could be killed and the probability of these fatal scenarios. Calibration of these estimates is challenging because historical landslide fatalities data have not been commonly available in a format that facilitates calibration of risk estimates, and, thankfully, because landslide deaths are uncommon in British Columbia. 
This article takes a step toward addressing this quantitative risk estimate calibration challenge. It is a synthesis of historical landslide fatalities in British Columbia, which can be used to calibrate regional-scale risk studies and inform site-specific landslide risk estimates. It describes trends in historical landslide fatality data, compares landslide fatality rates with other hazard types, and describes implications for forwardlooking landslide risk management practice.

Although it is specific to British Columbia, the methods for identifying and presenting landslide fatality trends could be modified and adopted for other world regions. As quantitative risk management frameworks become more common around the world (e.g., Malone, 2005; Corominas et al., 2014), there will be a need to calibrate landslide risk estimates. The most onerous task that precedes this calibration is collection of complete fatality datasets, and researchers are making great progress in this realm (e.g., Kirschbaum et al., 2015; Froude and Petley, 2018; Blais-Stevens, 2020). However, synthesis of these data is necessary to calibrate risk estimates and inform risk management decisions. This article provides a template for this type of synthesis.

\section{BRITISH COLUMBIA FATAL LANDSLIDE DATABASE}

A detailed compilation of historical landslide fatalities in British Columbia, which we refer to as the British Columbia Fatal Landslide Database, is provided as a Supplementary Table S1. The Geological Survey of Canada (Blais-Stevens, 2020) provides a map that illustrates the location of many of the fatal landslide events. The database includes fatalities from direct landslide burial and impact and indirect mechanisms like landslidegenerated tsunamis, train derailments, and vehicle crashes. It also includes a variety of settings and triggers ranging from failure of temporary excavations at mining operations and constructions sites to natural landslides impacting residences, including earthquake-triggered landslides. No landslide setting or type was intentionally omitted.

The compilation is based on information from the following key sources: 1) the Global Fatal Landslide Database (Froude and Petley, 2018), 2) a compilation of historical Canadian landslides that resulted in fatalities, from the Geological Survey of Canada (Blais-Stevens, 2020), and 3) a catalogue of historical flooding ${ }^{1,2}$ and landslide events in British Columbia (Septer, 2007a; Septer, 2007b).

\footnotetext{
${ }^{1}$ The British Columbia Fatal Landslide Database includes fatalities caused by erosion and sedimentation related to debris floods (Church and Jakob, 2020) because the debris flood process can overlap with debris flows in many steep creeks and can be indistinguishable from debris flows in newspaper descriptions. Similarly, the Canadian Disaster Database (Public Safety Canada, 2020) classify debris floods as 'landslides'.

${ }^{2}$ Fatality rate described throughout this article is estimated using a 10 -years rolling average of the annual fatalities in each year. The rolling average considers the 5 years before and after the year for which the fatality rate is assigned. It is not adjusted for population.
}

The Global Fatal Landslide Database is a database of fatal landslides that have occurred worldwide since 2004, based on systematic, daily searches of English-language news sources and reports that are available on the internet (Petley, 2012; Froude and Petley, 2018). The Geological Survey of Canada's compilation is a map and table of fatal landslides in Canada from 1771 to 2019 , based on review of technical reports, coroner's reports, newspaper articles, and information provided by colleagues in the landslide risk management field (Blais-Stevens, 2020). The reports by Septer (2007a); Septer (2007b) are chronological catalogues of newspaper clippings that describe damaging flood and landslide events that occurred in British Columbia between 1808 and 2006. The first documented fatal landslide with a known number of fatalities was in 1880 .

Many of the fatal landslide events $(\sim 60 \%)$ are listed in more than one of these sources, and where discrepancies were found (e.g. event date, number of fatalities), we tended to use the information reported in Blais-Stevens (2020) because BlaisStevens (personal communication, July 7, 2020) was generally aware of the discrepancies and reviewed multiple sources prior to selecting a value. The interpretations of landslide type, setting, cause and trigger, and whether members of the public or workers were killed, were made by the authors. The reports by Septer $(2007 a ; 2007 b)$ were particularly valuable for this interpretation because they tended to include descriptions of the landslide and flood events from eye-witness accounts reported by journalists. Interpretations were necessary because these accounts rarely used current landslide taxonomic terms, and did not explicitly mention all database categories. "Unknown" is listed in the British Columbia Fatal Landslide Database where no information was identified that could support an interpretation or inference.

Each data source acknowledges that landslide fatalities may be missing from their respective compilations. Combining the three data sources partially addresses these data gaps but does not fill all omissions. Particularly, older events that resulted in only one or two fatalities are likely to be missing from the British Columbia Fatal Landslide Database, and this may explain why many of the years before 1950 have no recorded fatal landslide events. Although the error caused by missing data is unknown, the database is interpreted to be complete enough to support the conclusions of this article. Firstly, each data source is described as comprehensive, intending to be a compilation of all "known" events. Secondly, multiple fatality events, which have the greatest influence on overall trends, are relatively more likely to be captured by news articles and reports that are available to researchers (Petley, 2009; Sepúlveda and Petley, 2015). Thirdly, recent trends in landslide fatalities are the most relevant to risk assessment calibration, and recent events are most likely to be captured in the data because both the Global Fatal Landslide Database and the Geological Survey of Canada compilation have tracked landslide fatalities since 2004 using independent methods. Petley (2012) estimated that the Global Fatal Landslide Database slightly underestimates true landslide 
TABLE 1 | Summary of british columbia fatal landslide database from 1880 to 2019.

Item

Number of fatal landslide events

Number of multiple-fatality events

Number of events causing $>10$ deaths

Length of record (years)

Years with at least one fatality

Total number of fatalities

Maximum fatalities in a single event

Median fatalities per event

Average fatalities per year

\section{Value}

\section{3}

48

5

140

77

390

54

1.0

2.8
Comment

Events that caused more than one fatality

1880 through 2019

Rock avalanche at jane camp, britannia mine complex in 1915 More than half of the events caused one fatality

Total fatalities divided by length of record

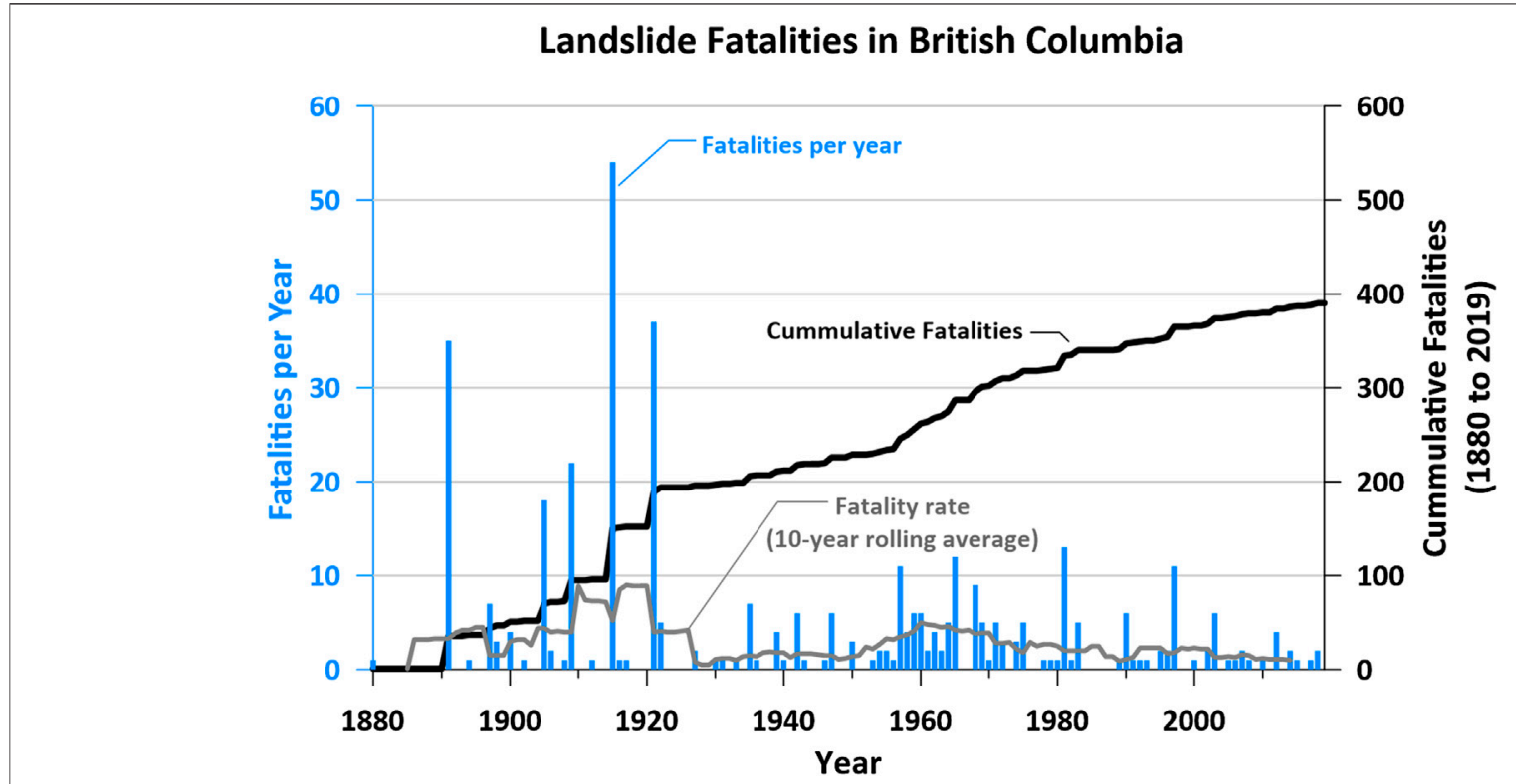

FIGURE 1 | Landslide fatalities and landslide fatality rate $^{2}$ in British Columbia between 1880 and 2019.

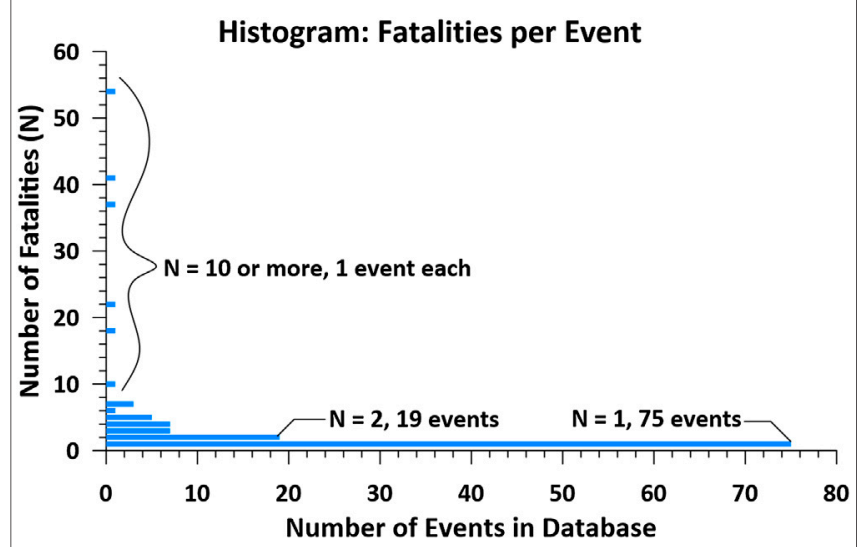

FIGURE 2 | Histogram of number of fatalities per fatal landslide in British Columbia between 1880 and 2019.

impacts, with a typical error of up to $15 \%$. By extension, the British Columbia Fatal Landslide Database may similarly underestimate landslide fatalities for the 2004-2019 period.

\section{LANDSLIDE FATALITY TRENDS}

\section{0-2019}

Between 1880 and 2019 there were 390 recorded fatalities caused by landslides in British Columbia (Table 1; Figure 1). This equates to an average of 2.8 fatalities per year, although this number is skewed by several high-fatality events that occurred more than 100 years ago. Most fatal landslides (62\%) caused a single fatality (Figure 2). All events causing more than 20 fatalities were deaths to workers and residents of work camps during and before 1921, including the highest fatality event: a rock avalanche at Jane Camp in the Britannia Mine Complex in 1915 causing 54 fatalities (Septer, 2007b). A plot of cumulative fatalities (Figure 1) demonstrates that the rate of landslide fatalities has steadily decreased with time following a cluster of many landslide events in the late 1950s and early 1960s.

\section{0-2019}

This section focuses on landslide fatality trends in the second half of the database, the 70 years period after 1950. Recent trends in 


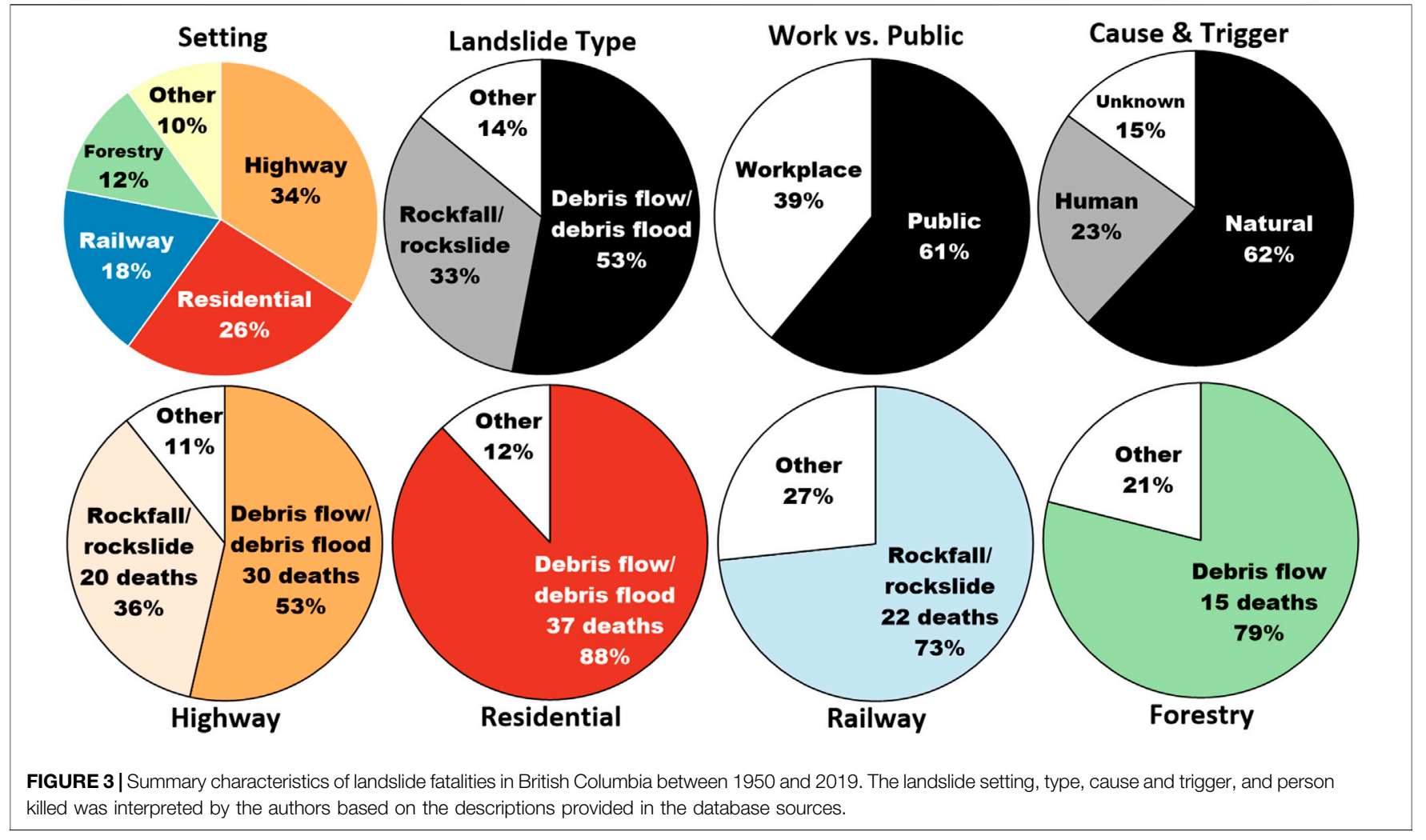

killed was interpreted by the authors based on the descriptions provided in the database sources.

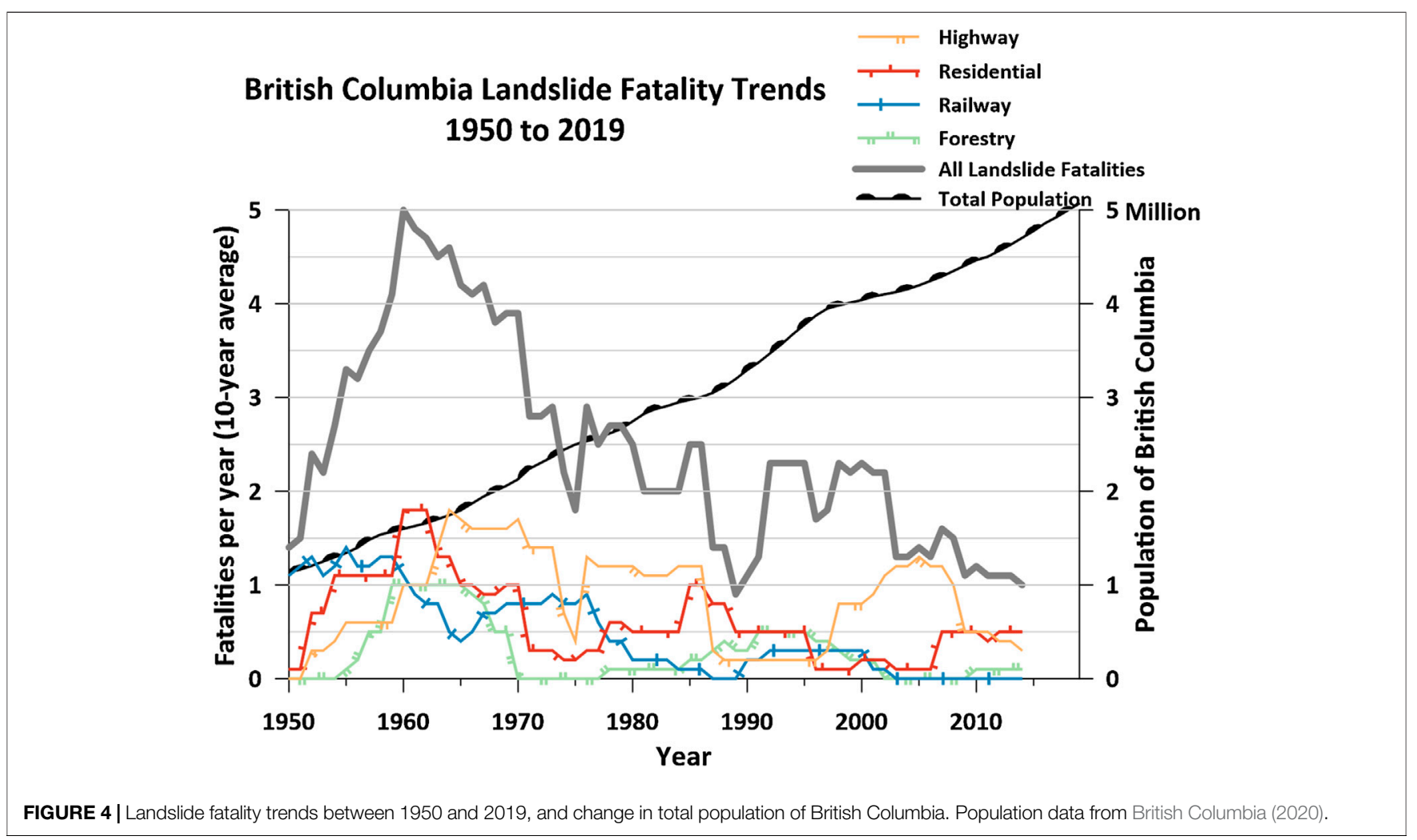




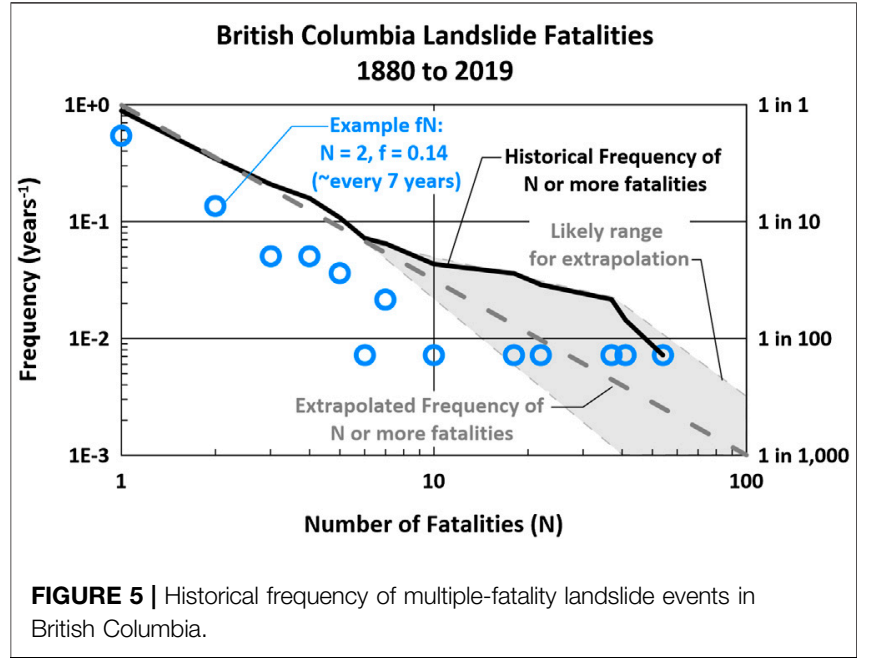

landslide fatalities are more relevant than the full database for calibrating forward-looking risk estimates because current risk estimates are specific to demographics, settlement patterns, and activities of modern times. In addition, the database is likely to be more complete and accurate in more recent times due to the wider coverage of newspapers and more formal reporting of deaths.

Figure 3 summarizes characteristics of these landslide fatalities, and Figure 4 illustrates the change in fatality rate with time. The overall fatality rate declined steadily from approximately five fatalities per year in 1960 to one fatality per year in 2019. This five-fold reduction in landslide fatality rate has occurred despite a five-fold increase in the population of British Columbia (Figure 4), dropping from 0.3 to 0.02 deaths per 100,000 people per year from 1960 to 2019. This result may be due to a change in settlement patterns with time, transitioning from a greater relative prevalence of rural communities in mountainous areas to greater densification of urban areas away from landslide hazards in recent times. It is also a credit to continually improving landslide risk management practice, which appears to be outpacing the rate of new development in landslide-prone terrain.

The most common setting for a fatal landslide is a highway. Debris flows and debris floods are more likely than rockfalls to kill people on highways. For example, several multiple-fatality events (e.g., M Creek in 1981, Green Mountain Road in 1942, Rutherford Creek in 2003) occurred when cars drove into the abyss left by a debris flow or debris flood that washed away a bridge. The landslide fatality rate on highways has averaged 0.8 landslide fatalities per year (56 total fatalities), fluctuating in the range between 0.5 and 1.5 .

Homes are the second most common setting. Most landslides causing residential fatalities are debris flows and debris floods. The landslide fatality rate in residential settings has averaged 0.6 landslide fatalities per year ( 42 total fatalities), and has declined with time, averaging 0.4 (20 total fatalities) since 1970.

Railways are the third most common setting. Most of these fatalities are caused by rockfalls and rockslides, particularly due to rockfall deposits on the track that lead to train derailment. These events tend to kill one or two railway workers who are operating the train when it derails. The overall landslide fatality rate on railways has averaged 0.4 fatalities per year (30 total fatalities) but has declined from more than one fatality per year in the 1950s to zero landslide-related fatalities between 1998 and 2019. The falling trend in landslide fatality rate shows a clear improvement with time of landslide risk management practice on the railways.

The forestry industry is the fourth most common setting, resulting in 19 deaths between 1950 and 2019. Most of the landslide fatalities in the forestry industry are caused by debris flows and debris avalanches. The overall landslide fatality rate in the forestry industry has averaged 0.3 fatalities per year, and has declined with time, with only one landslide-related fatality recorded between 1997 and 2019. Landslide fatalities have also occurred during hydropower construction (four deaths), recreation (four deaths), and mining activities (one death).

Overall, debris flows and debris floods cause most landslide fatalities, and the people killed tend to be members of the public who are traveling on highways or are at home. Most fatal landslides have a natural cause and trigger, such as rainfall causing a landslide on a natural slope. However, approximately a quarter of fatal landslides are related to human activities such as rock cuts on highways and railways.

TABLE 2 | Cause of death in British Columbia.

\begin{tabular}{lccc}
\hline Cause of death & $\begin{array}{c}\text { Average } \\
\text { deaths per year }\end{array}$ & Mortality rate ${ }^{\text {a }}$ & $\begin{array}{c}\text { Source } \\
\text { and date range }\end{array}$ \\
\hline All causes & 37,295 & 1 in 130 & BCCS ${ }^{\mathrm{b}} 2015-2019$ \\
Motor vehicle accident & 326 & 1 in 14,000 & BCCS 2008-2018 \\
Accidental drowning & 74 & 1 in 62,000 & BCCS 2008-2016 \\
Pedestrian killed by vehicle & 56 & 1 in 84,000 & BCCS 2010-2019 \\
Residential fire & 33 & 1 in 130,000 & BCCS 2007-2011 \\
Landslides & 1 & 1 in 5 million & This article 2007-2019
\end{tabular}




\section{British Columbia \\ Cause of Death}

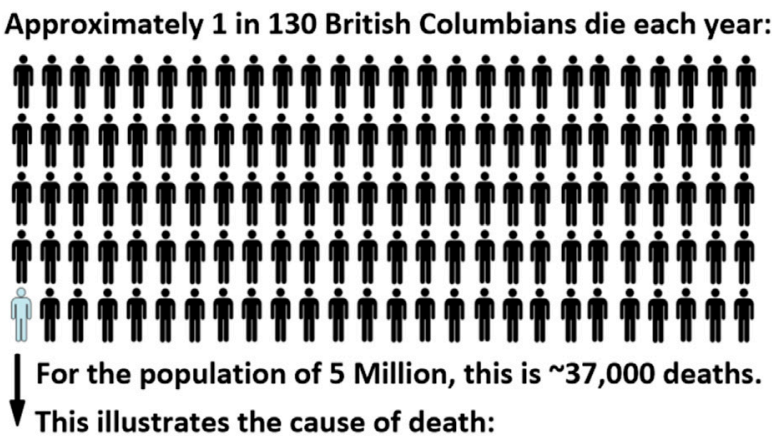

Other diseases

13,000 deaths

1 in 3

Cardiovascular diseases

11,000 deaths

3 in 10

Cancer

10,600 deaths

3 in 10

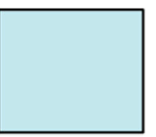

Other accidents

1,200 deaths; 1 in 30

\section{Suicide}

600 deaths; 1 in 60

Motor vehicle accidents 300 deaths; 1 in 100

Homicide; 100 deaths; 1 in 300

- Landslides; 1 death; 1 in 37,000

FIGURE 6 | Comparison of landslide deaths with other causes of death in British Columbia (Statistics Canada, 2009; British Columbia Coroners Service 2020). The area of each cell is proportional to the number of deaths per year.

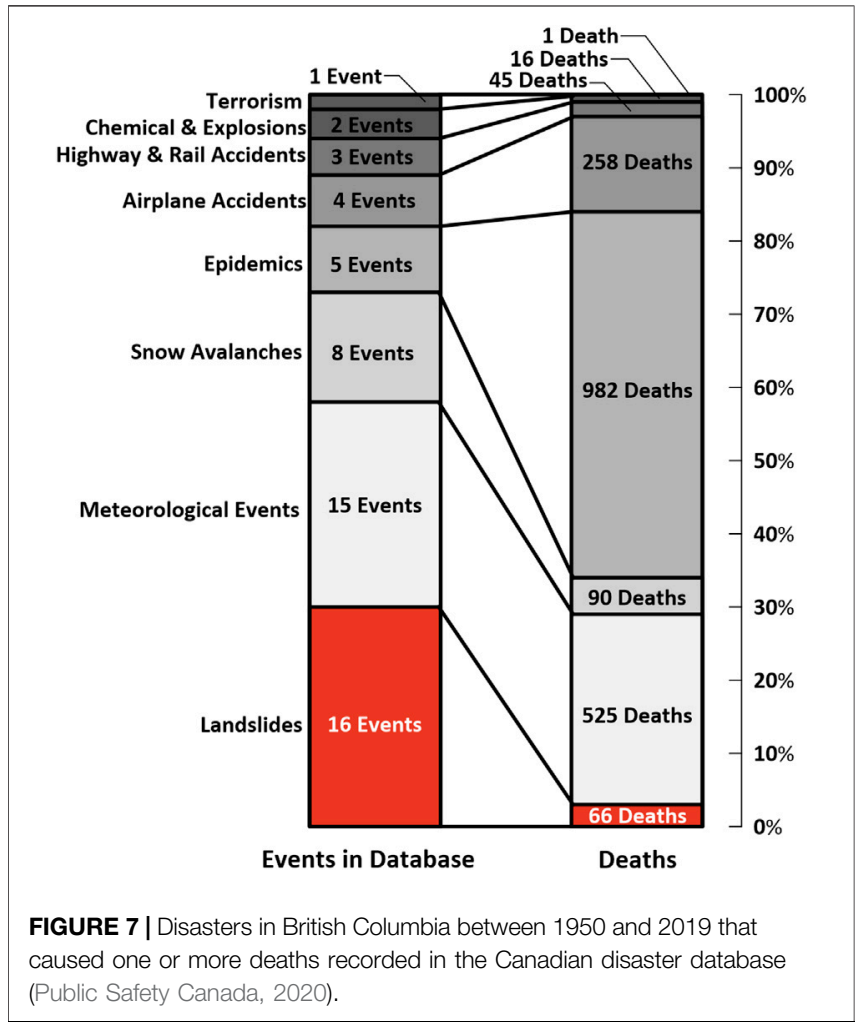

\section{EVENTS CAUSING MULTIPLE FATALITIES}

Landslide risk analysts commonly estimate the number of people that could be killed at a particular landslide hazard site or across a region in what is called a "societal" or "group" risk estimate (Strouth and McDougall, 2020). This information is often presented on a loglog diagram comparing number of fatalities with probability. Two versions of this diagram (i.e., $\mathrm{fN}$ and $\mathrm{FN}$ ) are common. An " $\mathrm{fN}$ " diagram compares the number of fatalities $(\mathrm{N})$ in a single landslide scenario with the probability (or frequency) of that scenario (f). $\mathrm{fN}$ diagrams consist of a series of dots that represent each assessed scenario. An "FN" diagram combines the scenarios into a single curve that describes the probability (or frequency) of " $\mathrm{N}$ or more" fatalities for the full dataset.

Figure 5 is a combined $\mathrm{fN}$ and $\mathrm{FN}$ diagram that displays the historical frequency of single-fatality and multiple-fatality landslide events in British Columbia. The blue dots ( $\mathrm{fN}$ ) represent the frequency of events causing a specific number of fatalities. For example, events causing exactly two fatalities occur at a frequency of approximately 1 in 7 years. Each of the $\mathrm{fN}$ dots was calculated simply by dividing the total number of events causing exactly $\mathrm{N}$ fatalities in the British Columbia Fatal Landslide Database by the record length (140 years, 1880 through 2019). The frequency is 1 in 140 years where there is only one event that resulted in $\mathrm{N}$ fatalities in the database. This truncation in the record length skews the FN curve. An interpreted extrapolation of the FN curve is included in Figure 5 that approximates an FN curve without data truncation. The shape of this extrapolation and the possible range for the 
extrapolation are based on the general shape of FN curves for natural hazard fatalities (e.g., blizzards, earthquakes, floods) in the United States provided in Baecher et al. (2015). FN curves tend to be linear in log-log space before becoming asymptotic at a limiting number of fatalities $(\mathrm{N})$ that is related to the population exposed to individual hazard events.

The historical $\mathrm{fN}$ and $\mathrm{FN}$ information can be used to inform calibration of forward-looking societal landslide risk estimates in British Columbia. It has more application for calibration of regional estimates, but it could also be considered an upperbound curve for comparison against societal risk estimated at an individual hazard site or a compilation of hazard sites. For calibration at a specific hazard site, it may be reasonable to shift the curve proportionally with the variation in the size of the population at risk at the specific site compared to the population at risk in British Columbia (see method used by Sobkowicz et al., 1995; Hungr et al., 2016). The authors are currently working on methods for calibrating life-loss risk estimates at individual sites based on this historical data, and evaluating how similar calibration could be done with data available in other world regions.

\section{LANDSLIDE LIFE-LOSS RISK IN CONTEXT}

Landslide fatalities are rare in British Columbia (Table 2; Figure 6) compared to other causes of death. For example, during the last decade, when there has averaged only one landslide death per year, the British Columbia Coroners Service (2020) reports 326 deaths per year in motor vehicle accidents, 74 deaths per year by drowning, and 33 deaths per year by residential fires. Table 2 compares landslide fatalities with other types of accidental deaths. Figure $\mathbf{6}$ places average landslide fatality risk in British Columbia into context with the most common causes of death, which are primarily diseases.

Despite this low relative death toll, landslides remain an important hazard demanding attention and resources from risk managers. For example, Public Safety Canada maintains the Canadian Disaster Database (Public Safety Canada, 2020), which "contains detailed disaster information on more than 1,000 natural, technological and conflict events (excluding war) that have happened since 1900 at home or abroad and that have directly affected Canadians." A “disaster" is defined by Public Safety Canada as an event that kills 10 or more, affects 100 or more, requires national or international assistance, has historical significance, or causes damage that cannot be overcome by the affected community on its own. In the Canadian Disaster Database, landslides are the most common type of "disaster" that occurred in British Columbia between 1950 and 2019, representing 30\% of the 54 total 'disasters' that resulted in at least one fatality. Despite the large number of events, landslides were responsible for only $3 \%$ of the total fatalities (Figure 7). Landslides are classified as "disasters" in British Columbia because they tend to cause damage that cannot be overcome by the affected community on its own, thus requiring assistance from provincial and federal emergency management agencies.
Taken together, this context suggests that life loss may not generally be the most important landslide consequence to consider for risk management decision making in British Columbia. Other consequences, such as property destruction, economic losses, and infrastructure or transportation service disruption (Porter et al. 2019), may provide a stronger metric. This suggestion supports arguments in Strouth and McDougall (2020) that advocate for risk evaluation tools that consider economic impacts and costeffectiveness of landslide risk management measures in addition to life-loss risk tolerance thresholds.

\section{CONCLUSION}

Landslides are the most common type of disaster that occurs in British Columbia, and the number of people exposed to landslide hazards continues to increase as the population grows. So far, the evolution of landslide risk management practice has outpaced development pressures in landslide-prone terrain, leading to a reduction in overall landslide life-loss risk with time in British Columbia. A recent step in this evolution has been toward a proactive, forward-looking quantitative risk management framework. This article provides quantitative information that can inform calibration of those life-loss risk estimates, including: in the last decade there has been approximately 1.0 landslide-caused fatalities in British Columbia per year, and approximately half of these are related to debris flows and debris floods that impact homes, whereas the other half are related to rockfalls, debris flows, and debris floods that impact highways. Due to the small number of landslides, these trends are sensitive to individual events (particularly multiplefatality events) and should be updated as future fatal landslides occur. Regardless, historical life-loss risk from landslides is low relative to other disaster types tracked in Canada. This suggests that other consequences like building damage, economic losses, and road and utility service disruptions may be driving the classification of landslides as "disasters," and perhaps ought to be a relatively stronger focus of landslide risk management practice in British Columbia. Similar studies in other world regions are needed to better understand landslide risk trends, importance of landslide risk relative to other hazard types, and relationships between lifeloss and economic risks posed by landslides.

\section{DATA AVAILABILITY STATEMENT}

The original contributions presented in the study are included in the article/Supplementary Material, further inquiries can be directed to the corresponding author.

\section{AUTHOR CONTRIBUTIONS}

AS compiled the database, analyzed the data, and wrote the draft manuscript. SM helped form the research objectives, supported the analyses and interpretations, and contributed to, reviewed, and edited the text. 


\section{FUNDING}

The publishing fee was supported by a grant from the University of British Columbia.

\section{ACKNOWLEDGMENTS}

The British Columbia Fatal Landslide Database relies heavily on the data that was collated by Andrée Blais-Stevens (BlaisStevens, 2020). Lucy Myrol helped to compile, review, and format the database table. Michael Porter suggested the need

\section{REFERENCES}

Baecher, G., Abedinisohi, F., and Patev, R. (2015). Societal risk criteria for loss of life concepts, history, and mathematics. College Park, MD: University of Maryland.

Blais-Stevens, A. (2020). Geological Survey of Canada Open File 8392. Historical landslides that have resulted in fatalities in Canada (1771-2019). doi:10.4095/ 326167

British Columbia. (2019). Modernizing BC's emergency management legislation. Available at https://engage.gov.bc.ca/app/uploads/sites/121/2019/10/modernizing bcs_emergencymanagement_legislation.pdf (Accessed September 11, 2020).

British Columbia. (2020). Annual population, july 1, 1867-2019. Available at: https://www2.gov.bc.ca/gov/content/data/statistics/people-population-community/ population/population-estimates (Accessed September 11, 2020).

British Columbia Coroners Service (2020). Statistical reports on deaths in British Columbia. Available at: https://www2.gov.bc.ca/gov/content/life-events/death/ coroners-service/statistical-reports (Accessed September 11, 2020).

Church, M., and Jakob, M. (2020). What is a debris flood? Water Resour. Res. 56 (8), e2020WR027144. doi:10.1029/2020wr027144

Corominas, J., van Westen, C., Frattini, P., Cascini, L., Malet, J. P., Fotopoulou, S., et al. (2014). Recommendation for the quantitative analysis of landslide risk. Bull. Eng. Geol. Environ. 73 (2), 209-263. doi:10.1007/s10064-0130538-8

Froude, M. J., and Petley, D. N. (2018). Global fatal landslide occurrence from 2004 to 2016. Nat. Hazards Earth Syst. Sci. 18, 2161-2181. doi:10.5194/nhess-182161-2018

Hungr, O., Clague, J., Morgenstern, N., VanDine, D., and Stadel, D. (2016). “A review of landslide risk acceptability practices in various countries," in Proceedings of the 12th International Symposium on Landslides. 12-19.

Kirschbaum, D., Stanley, T., and Zhou, Y. (2015). Spatial and temporal analysis of a global landslide catalog. Geomorphology 249, 4-15. doi:10.1016/j.geomorph. 2015.03.016

Malone, A. W. (2005). "The story of quantified risk and its place in slope safety policy in Hong Kong," in Landslide hazard and risk (Hoboken, NJ: John Wiley \& Sons Ltd.), 643-674. doi:10.1002/9780470012659.ch22

Petley, D. (2012). Global patterns of loss of life from landslides. Geology 40 (10), 927-930. doi:10.1130/g33217.1

Petley, D. (2009). On the impact of urban landslides. Geological Society, London, Eng. Geol. Sp. 22, 83-99. doi:10.1144/EGSP22.6

Porter, M., Jakob, M., Holm, K., and McDougall, S. (2017). "Risk-based landslide safety assessments in Canada," in Proceedings of the North American symposium on landslides, Roanoke, VA, June 4-8, 2017. for a historical benchmark that could be used for calibration. Additionally, we thank the journal editors and reviewers for their constructive feedback and support; suggestions and edits from Nicholas Roberts and José Pedro Matos greatly improved this article.

\section{SUPPLEMENTARY MATERIAL}

The Supplementary Material for this article can be found online at: https://www.frontiersin.org/articles/10.3389/feart.2021.606854/ full\#supplementary-material.

Porter, M., Van Hove, J., Barlow, P., Froese, C., and Bunce, C. (2019). "The estimated economic impacts of prairie landslides in western Canada," in Proceedings of the 72nd Canadian Geotechnical Conference, St. John's Newfoundland and Labrador.

Public Safety Canada. (2020). The Canadian disaster database. Available at: https:// www.publicsafety.gc.ca/cnt/rsrcs/cndn-dsstr-dtbs/index-en.aspx (Accessed September 11, 2020).

Septer, D. (2007a). Flooding and landslide events northern British Columbia 1820-2006. Province of British Columbia. Victoria, BC: Ministry of Environment.

Septer, D. (2007b). Flooding and landslide events southern British Columbia 1808-2006. Province of British Columbia. Victoria, BC: Ministry of Environment.

Sepúlveda, S., and Petley, D. (2015). Regional trends and controlling factors of fatal landslides in Latin America and the Caribbean. Nat. Hazards Earth Syst. Sci. 15, 1821-1833. doi:10.5194/nhess-15-1821-2015

Sobkowicz, J., Hungr, O., and Morgan, G. (1995). "Probabilistic mapping of a debris flow hazard area: cheekye Fan, British Columbia" in Proceedings of the 48th Canadian geotechnical conference, Vancouver, BC, September 25-27, 519-529.

Statistics Canada. (2012). Mortality, summary lists of causes-2009 (Canada: Minister of Industry). Available at: https://www150.statcan.gc.ca/n1/en/pub/ 84f0209x/84f0209x2009000-eng.pdf?st=8PHvvPZW (Accessed September 11, 2020).

Strouth, A., and McDougall, S. (2020). Societal risk evaluation for landslides: historical synthesis and proposed tools. Landslides. doi:10.1007/s10346-020-01547-8

United Nations Office of Disaster Risk Reduction. (2015). Sendai framework for disaster risk reduction 2015-2030.

Conflict of Interest: Author AS was employed by BGC Engineering Inc.

The remaining author declares that the research was conducted in the absence of any commercial or financial relationships that could be construed as a potential conflict of interest.

Copyright (C) 2021 Strouth and McDougall. This is an open-access article distributed under the terms of the Creative Commons Attribution License (CC BY). The use, distribution or reproduction in other forums is permitted, provided the original author(s) and the copyright owner(s) are credited and that the original publication in this journal is cited, in accordance with accepted academic practice. No use, distribution or reproduction is permitted which does not comply with these terms. 